\title{
Esophageal cancer: the rise of adenocarcinoma over squamous cell carcinoma in the Asian belt
}

\author{
Victoria J. Grille ${ }^{1}$, Stuart Campbell ${ }^{1}$, John F. Gibbs ${ }^{1,2}$, Thomas L. Bauer ${ }^{1,3}$ \\ ${ }^{1}$ Department of General Surgery, ${ }^{2}$ Department of Surgical Oncology, Hackensack Meridian Health School of Medicine at Seton Hall University, \\ Nutley, NJ, USA; ${ }^{3}$ Department of Surgery, Jersey Shore University Medical Center, Neptune, NJ, USA \\ Contributions: (I) Conception and design: All authors; (II) Administrative support: JF Gibbs, TL Bauer; (III) Provision of study materials or patients: \\ All authors; (IV) Collection and assembly of data: VJ Grille, S Campbell, JF Gibbs; (V) Data analysis and interpretation: VJ Grille, JF Gibbs; (VI) \\ Manuscript writing: All authors; (VII) Final approval of manuscript: All authors. \\ Correspondence to: Thomas L. Bauer, MD. Department of General Surgery, Jersey Shore University Medical Center, 1945 State Route 33, Neptune, \\ NJ 07753, USA. Email: Thomas.bauer@hackensackmeridian.org.
}

\begin{abstract}
Esophageal cancer is a common cancer worldwide with a high associated mortality rate. Amongst the two most frequent subsets of disease, squamous cell carcinoma (SCC) and adenocarcinoma (AC), there has been an epidemiologic shift towards adenocarcinoma over the last few decades. However, squamous cell carcinoma still predominates worldwide. Within Western countries, obesity has been associated with an increase in esophageal AC. A striking report from the World Health Organization (WHO) stated that worldwide obesity has tripled since 1975. In 2016, the WHO reported that greater than 1.9 billion adults are overweight and over 650 million were obese. In this review our goal is to analyze the esophageal cancer trends of China, which is the largest contributor among the esophageal cancer "Asian belt." Our intent is to evaluate whether there is a correlation between the rise in esophageal adenocarcinoma and obesity in this esophageal cancer "hotspot." With further analysis, the high-risk populations that are identified can be targeted to implement preventative strategies. This focus will aid in decreasing the burden of esophageal cancer at the global health level by addressing preventative strategies, such as screening endoscopy and lifestyle modifications. For example, WHO developed a global action plan on physical activity in response to the rise in obesity worldwide. Prevention is key to decreasing the rate of esophageal adenocarcinoma as majority of cases are diagnosed in the late stages leading to high mortality rates.
\end{abstract}

Keywords: Esophageal cancer; adenocarcinoma; global; Asian esophageal belt; prevention

Submitted Feb 12, 2020. Accepted for publication Aug 17, 2020.

doi: 10.21037/jgo-2019-gi-08

View this article at: http://dx.doi.org/10.21037/jgo-2019-gi-08

\section{Introduction}

The incidence of esophageal cancers worldwide has been changing over the twentieth century, with rates of adenocarcinoma in comparison to squamous cell carcinoma (SCC). SCC historically has been the predominate neoplasm encompassing $90 \%$ to $95 \%$ of all esophageal cancers. However, the transition from SCC to adenocarcinoma (AC) has been noted by many epidemiological series and has been shown since the mid 1990's (1). This finding was initially observed in Western countries, with more recent increases in some Eastern countries as well as AC now accounts for $50 \%$ to $80 \%$ of esophageal cancer cases. In the United States, esophageal $\mathrm{AC}$ is the most predominant histology (2). This shift has led to much debate regarding the etiology of the disease, as well as the therapeutic options available for a malignancy with such rapid growth and high mortality with a 5 -year survival of $15-20 \%$ at best. Common risk factors are shared between the two classifications; however, characteristics have been identified that distinctly separate them. Although the increase is most notable in Western and high human 
development index (HDI) countries, the burden can also be recognized in the esophageal cancer "hotspots." The population comprising the "Asian esophageal cancer belt" represents more than $50 \%$ of all esophageal cancer cases worldwide, which allows for a large population size along with a broader array of "hotspots" that are easily compared. Although the vast majority of these esophageal cancers are due to SCC, we hypothesize that AC is an emerging hidden issue. In this review we analyzed trends within China that could be contributing to the changing histological patterns of esophageal cancer. Specifically, the analysis of trends and contributing factors were evaluated with the ultimate goal of aiding the development of health care policies for screening and prevention to allow control measures in the future. Screening high-risk populations with endoscopy has shown to be beneficial, however, a set of global guidelines still needs to be established to define who should be chosen for the screening process.

\section{Squamous cell carcinoma of the esophagus}

Esophageal SCC is predominant in the esophageal cancer "Asian belt" (Figure 1), including Northern Iran, Central Asia, and North-Central China with an incidence estimated as high as 100/100,000 annually (3). In western countries, including the USA, the incidence of esophageal SCC has been declining over the last several decades, and esophageal AC now predominates (4). Although the general trend in the US is from esophageal SCC to AC, this is disproportionate among all population subgroups in the US; African American males are 7 times more likely be diagnosed with esophageal SCC than esophageal AC, and US whites are 4 times more likely to be diagnosed with esophageal AC than SCC (5). Although most Western societies have the same reduction in esophageal SCC as the US, it is noted that SCC incidence rates are predicted to remain constant in areas such as the UK and Australia (6). Risk factors for esophageal SCC include smoking and alcohol use, diet and nutrition, and HPV. Changes in smoking and alcohol usage in Western countries has decreased the incidence of esophageal SCC, but worldwide esophageal SCC remains a major health concern.

\section{Smoking and alcobol}

Smoking has been known to be a causal risk factor for esophageal SCC for many years now, increasing the risk 3-7-fold in current smokers (7-9). Smoking cigars and pipes have also been shown to increase the risk of esophageal SCC, although to a lesser degree than cigarettes $(10,11)$. Changes in smoking patterns, especially in Western countries, is believed to contribute to the decline in incidence of esophageal SCC (12). Alcohol consumption has also been shown to increase rates of esophageal SCC independently $(13,14)$, and synergistically with tobacco consumption (15). Alcohol consumption in excessive amounts ( $>3$ drinks per day) increases cancer risk 3-5fold, regardless of the type of alcohol $(7,16)$. Even small quantities of alcohol consumption of less than $10 \mathrm{~g} / \mathrm{day}$, which correlates to one small glass of wine, have been shown to increase esophageal SCC risk (17). In general the incidence of esophageal SCC is decreasing in the US. However, it is still 7 times more frequent in African Americans in the US, likely due to alcohol and tobacco use patterns $(16,18,19)$. In 2016 a case control observational study including 703 patients with SCC did show an increased risk of esophageal cancer with second-hand smoke in a dose dependent manner (20). In terms of second hand smoke and the associated risk of esophageal cancer, further studies are needed to determine if there is an associated risk.

\section{Diet and nutrition}

There are many associations between diet, hot beverages, and nutritional deficiencies that have been implicated with esophageal SCC. Diets high in pickled vegetables and $\mathrm{N}$-nitrosamines are commonly found in China and Eastern countries and have been linked to esophageal SCC $(16,21,22)$. Maté, a tea consumed either hot or cold, contains polycyclic aromatic hydrocarbons, a known carcinogen. Maté is heavily consumed in South America where there is a high incidence of esophageal SCC (16). Certain hot beverages and prepared food have also been hypothesized to be associated with esophageal SCC, thought to be due to thermal injury (23). Several studies have also shown that diets deficient in fruits and vegetables, zinc, selenium and vitamins are also associated with increased rates of esophageal SCC (16,24-26). Nutritional deficiencies are often seen with alcohol use and likely contribute to the increased rates of esophageal SCC in alcohol users. Betel nuts are the seeds of the fruit of the areca palm, which grows in the tropical Pacific, Southeast and South Asia, and parts of east Africa. It is very popular in areas such as Taiwan and India, and has addictive properties due to the energy boost it produces. The association between betel nut and esophageal cancer has been in question for many 


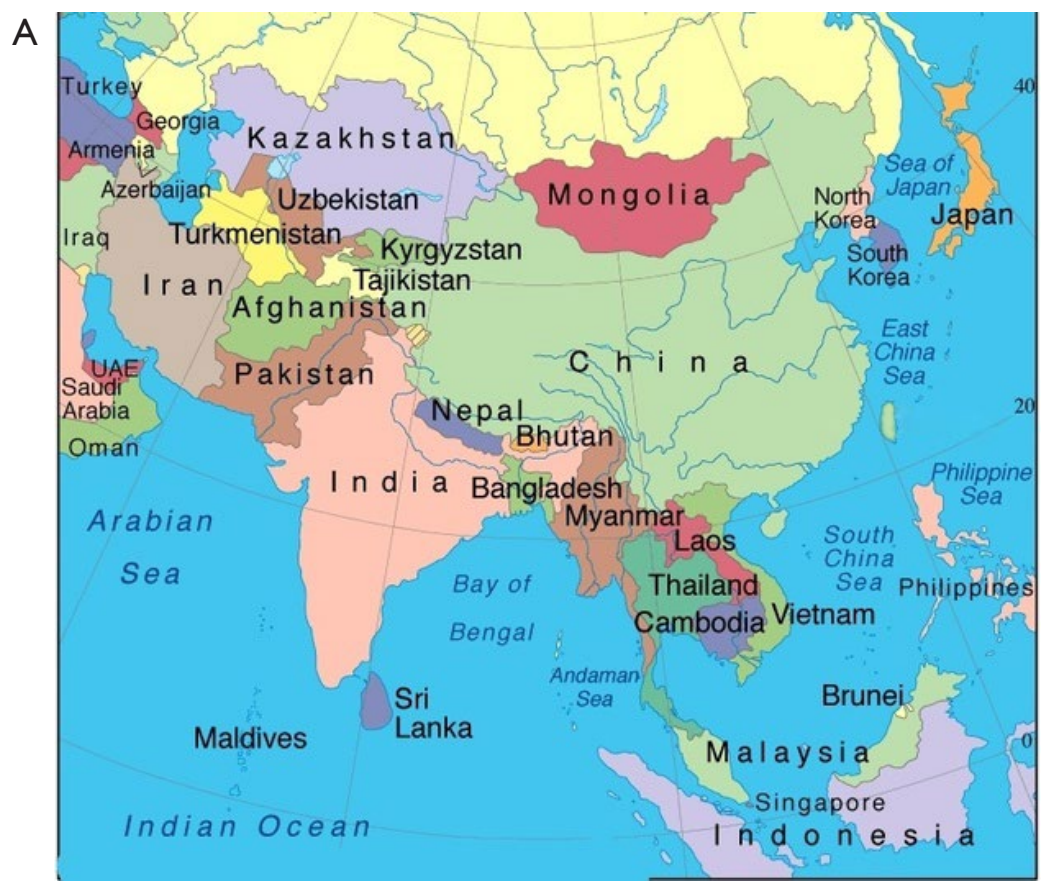

B

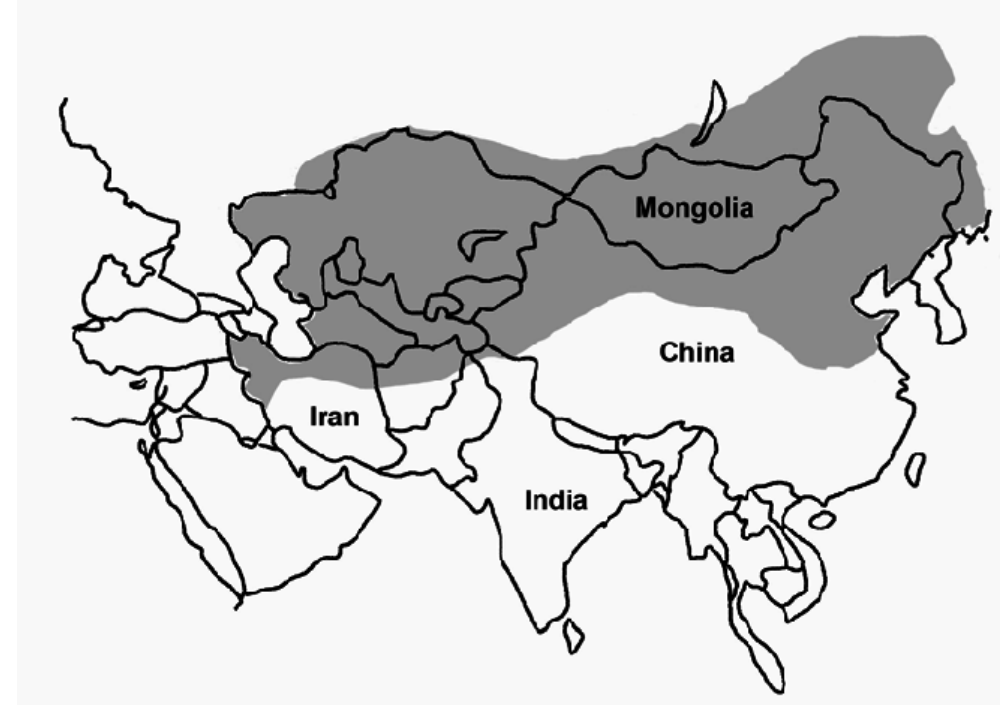

Figure 1 The Central Asian Esophageal Cancer Belt extending from Iran to China. Including countries and regions, such as Turkmenistan, Mongolia, Tajikstan, Bangladesh, Turkey, Iran, north-central China. The Asian Esophageal Cancer Belt accounts for more than 50\% of all esophageal cancers worldwide. (A) Geographic reference with labeled countries (B) Geographical boundaries of the Asian Esophageal Belt. 

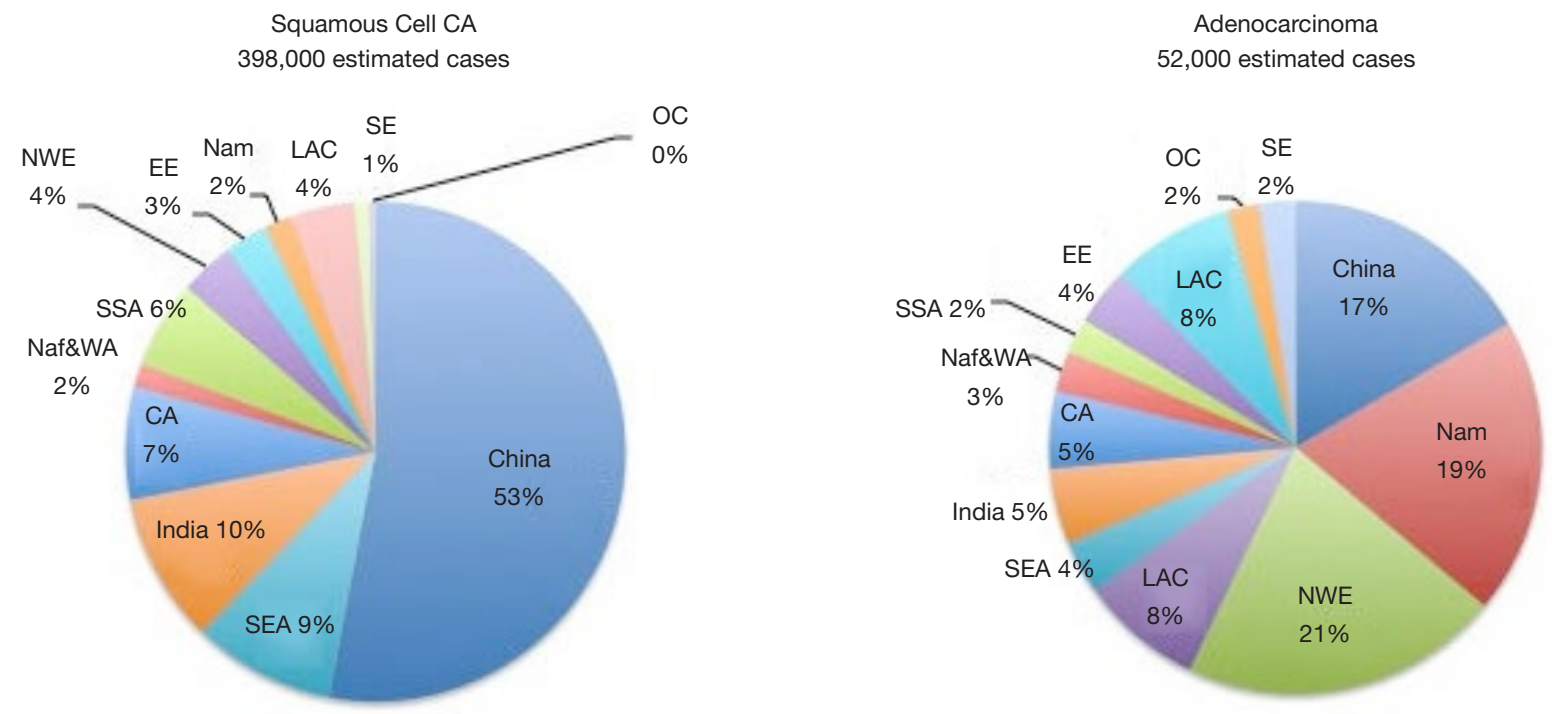

Figure 2 China represents 53\% and 18\% of global esophageal SCC and AC respectively. Regional distribution of estimated esophageal cancer cases by histological subtype in 2012. CA, Central Asia; EE, Eastern Europe; LAC, Central \& Southern America and Caribbean; NAm, Northern America; NAf \& WA, Northern Africa/Western Asia; NWE, North Western Europe; OC, Oceania; SE, Southern Europe; SEA, South-East Asia; SSA, Sub-Saharan Africa.

years due to the high incidence of SCC in the areas where it is popular. In 2012 a meta-analysis of case-control studies ( 2,836 cases; 9,553 controls) was done that showed betel nut chewing independently was associated with an increased risk of SCC. However, when combined with tobacco smoking the risk increased substantially (27).

\section{Human papilloma virus (HPV) related to esophageal cancer}

Human papilloma virus is a DNA virus well associated with SCC of the cervix, penis, oropharynx and anus. It can also affect the esophagus similarly due to the squamous histological similarities as these other locations. Virus subtypes HPV16 and HPV18 are the oncogenic subtypes associated with cervical cancer, however, the association between HPV and esophageal SCC has not been well established (28). Studies investigating HPV in esophageal SCC found the virus in tumor cells ranging from 0-70\% (29). Other studies, however, did not find HPV DNA integrated into the tumor genome (30). A recent article did identify a three times higher incidence of esophageal cancer in HPV positive individuals. In terms of prognosis of esophageal cancer due to HPV infection, Guo et al. performed a meta-analysis of 1184 cases to determine the associated progression of esophageal cancer (31). They were unable to show that there was any prognostic utility of the virus and its contributing factors. This analysis was limited by the degree of heterogeneity in the HPV subtypes. Of the studies that were included in the meta-analysis, only one was able to show a good survival prognosis among HPV positive patients with esophageal SCC. The HPV vaccine is unlikely to have a significant effect on rates of esophageal SCC worldwide since vaccination is typically performed in western countries. Further work is required to more clearly identify the link between HPV and certain types of ESCC (32).

\section{Squamous cell carcinoma in Cbina}

In 2012, there was estimated to be 398,000 global cases of SCC, with the Asian belt comprising over 70 percent of the global total. Although esophageal cancer is decreasing in China over the last few decades, it is responsible for over $50 \%$ of all esophageal cancers. Figure 2 quantifies the global burden of esophageal cancer by histological type (33). Further studies have been underway in China to identify the major risk factors of the disease. Other studies reported a higher incidence in rural areas and men, with rates in rural areas double that of urban (34). This most likely is 


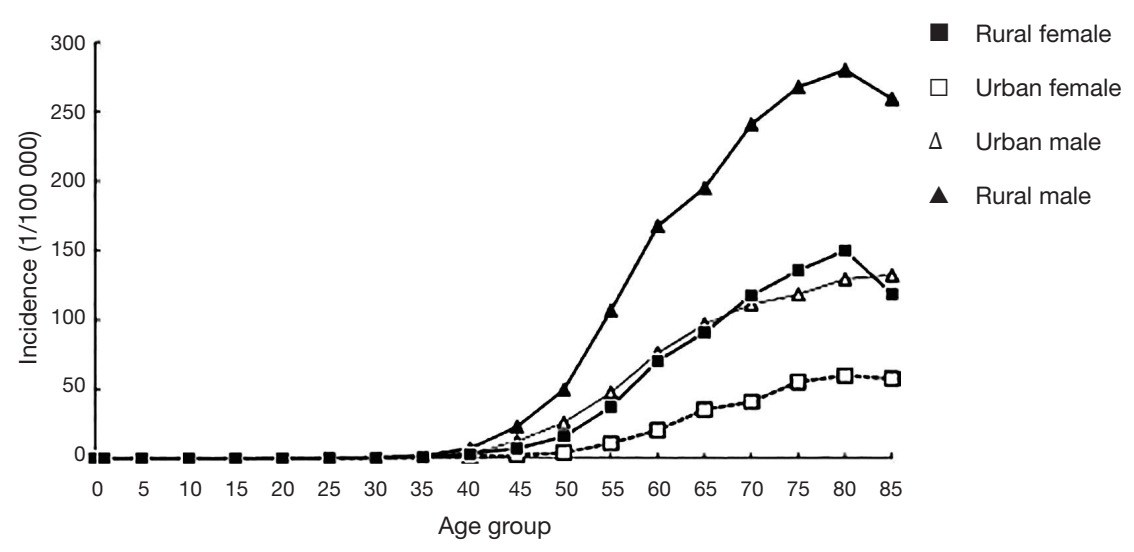

Figure 32011 age-specific esophageal cancer incidence in China. Adapted from (34). Urban male and rural female incidence rates of esophageal cancer are comparable. Similarities in their lifestyle, such as obesity, could be associated.

related to socioeconomic status and lifestyle with common risk factors like those discussed previously. Figure 3 shows the incidence of esophageal cancer in both sexes and their country of residence in China.

\section{Rise of adenocarcinoma of the esophagus}

Over the past four decades, the frequency of adenocarcinoma of the esophagus, esophagogastric junction (EGJ), and gastric cardia has been increasing dramatically (35). The rising trend was first noted in Western countries with it surpassing SCC in the United States; however, recently increases have been noted in Eastern countries as well. This has led to more focus on the etiology behind development of esophageal adenocarcinoma, as well as the risk factors associated with its increasing frequency.

Adenocarcinoma arises from intestinal type cells (transition of squamous to intestinal type histology) and is more frequently located in the lower third of the esophagus. Barrett's esophagus and chronic gastroesophageal reflux disease are the main risk factors associated with its pathology, with Barrett's esophagus associated with a 30 to 125 -fold increase in esophageal adenocarcinoma (36). Barrett's metaplasia results from chronic reflux and leads to injuring the esophageal squamous cell epithelium and transition to metaplastic columnar epithelium. With further injury and genetic changes, progression occurs in a metaplasia-dysplasia-adenocarcinoma sequence.

The other risk factors of esophageal adenocarcinoma that we will discuss in this review include obesity, smoking, diets high in saturated fat and red meat, treatment of Helicobacter pylori and medications that relax the esophageal sphincter. All these factors have a direct association with the increase in esophageal adenocarcinoma.

\section{Obesity and nutrition}

The risk for esophageal adenocarcinoma is associated with an increasing BMI, due to gastroesophageal reflux disease in obese individuals. Obesity is defined based on body mass index (BMI), which is a weight-to-height ratio classification that is defined as a person's weight in kilograms divided by the square of their height in meters $\left(\mathrm{kg} / \mathrm{m}^{2}\right)$. Obesity is a BMI greater than or equal to 30 (37). Hiatal hernias are also more common in individuals with higher BMIs, which then leads to higher risk of reflux disease as well. With the understanding of Barrett's esophagus and the transition from metaplasia-dysplasia-cancer, we can see how this relationship will lead to higher incidence of esophageal adenocarcinoma with higher BMI.

In addition to increased BMI, low consumption of fruit and vegetables is an important risk factor for the development of adenocarcinoma of the esophagus. Studies have shown an inverse association between fruit and vegetable consumption and esophageal adenocarcinoma. On the contrary, diets high in calories and fat have a direct association with esophageal adenocarcinoma. Diets high in fiber, lutein, niacin, vitamin B6, and zinc were associated with a decreased cancer risk (4).

\section{Barrett's esophagus and gastroesophageal reflux disease (GERD)}

Generally, it is accepted that Barrett's esophagus develops 
from GERD, and that most adenocarcinomas develop from chronic reflux of acidic gastric contents into the lower portion of the esophagus eventually leading to malignant transformation at the cellular level (38). The initial intestinal metaplasia is defined as a transition of the esophageal squamous cells to tall columnar cells, which leads to a 30fold increased risk of an individual with Barrett's esophagus to develop esophageal cancer compared to the general population (39). In this issue, Grover et al. identified a shift in the normal esophageal microbiome in the setting of GERD or Barrett's esophagitis toward gram-negative bacterial organisms. This shift is postulated to contribute malignant transformation to esophageal adenocarcinoma (40). Due to the moderate to high probability of Barrett's esophagus transforming into cancer, individuals with highrisk dysplasia require frequent endoscopic surveillance throughout their lifetime.

Individuals with GERD have the classic symptoms of heartburn and acid regurgitation, and the prevalence of the disease varies significantly among different countries (41). There has been a significant increase in the prevalence of the disease over the past decade, most notably in North America. The incidence of reflux symptoms within geographic areas can reach above $25 \%$ on a monthly basis, which directly parallels the rising trends in esophageal adenocarcinoma (42). Statistics show that $10 \%$ of people with GERD will have underlying Barrett's esophagus that could potentially transform into esophageal adenocarcinoma if not managed appropriately. The symptoms of GERD seem to be equally distributed among men and women, however, men most notably have a higher incidence of complications from GERD including Barrett's esophagus, erosive esophagitis and esophageal adenocarcinoma (43).

\section{Smoking and alcohol}

Smoking and alcohol are known to be strong, modifiable risk factors for the development of squamous cell carcinoma of the esophagus, and together they have a synergistic effect on its development. Regarding esophageal adenocarcinoma, studies have been unable to prove a relationship between alcohol consumption and its development. However, studies have shown a direct correlation between tobacco smoking and development of esophageal adenocarcinoma, which exhibits a doseresponse pattern. The risk of development is found to be more than doubled and unlike squamous cell carcinoma, this risk persists even after smoking cessation (44).

\section{Medications that relax the esophageal sphincter}

Transient lower esophageal sphincter relaxation (TLESR) is a physiologic response of the lower esophageal sphincter to relax without swallowing. This response is triggered by gastric distension and will initiate either the reflux of air or fluid into the esophagus, dependent on patient positioning. Fluid most frequently refluxes while in the recumbent position, while air has been noted to reflux in the upright position. TLESR is observed in normal individuals as well as individuals with GERD. Studies have been done with HRM (high resolution manometry), which have shown that the frequency of TLESR seems to be similar in patients with and without GERD (45). Limited information is available regarding the duration of acid exposure to the esophagus during the episodes of TLESR. This should further be evaluated as the widespread use of medications that relax the lower esophageal sphincter (LES) has raised many questions regarding the potential association with the development of esophageal cancer. The LES-relaxing effect of these drugs promotes gastroesophageal reflux disease and has been documented for various classes of medication including nitroglycerines, anticholinergics, beta-adrenergic agonists, aminophyllines, benzodiazepines, and calcium channel blockers. As the incidence of esophageal adenocarcinoma has been rising, investigations have been done to document any increases risk from the use of these LES-relaxing medications. Lagergren and associates investigated the issue to determine the risk of developing adenocarcinoma of the esophagus and an estimated incidence rate ratio of 3.8 (95\% CI: 2.2-6.4) was found among daily, long-term users ( $>5$ years) of LES-relaxing drugs, compared with persons who had never used these drugs (46). A recent meta-analysis done by Alexandre and associates which involved 9,412 participants showed that esophageal adenocarcinoma was strongly associated with the use of theophylline [OR 1.55, 95\% confidence interval $\left.(\mathrm{CI}): 1.05-2.28 ; \mathrm{P}=0.03, \mathrm{I}^{2}=0 \%\right]$ and anticholinergic medications (OR 1.66, 95\% CI: 1.13 2.44; $\mathrm{P}=0.01, \mathrm{I}^{2}=84 \%$ ). However, calcium channel blockers and nitrates did not show an increased association with its development (47). As theophyllines and anticholinergics are used in the treatment of obstructive lung disease processes, this association with esophageal adenocarcinoma 

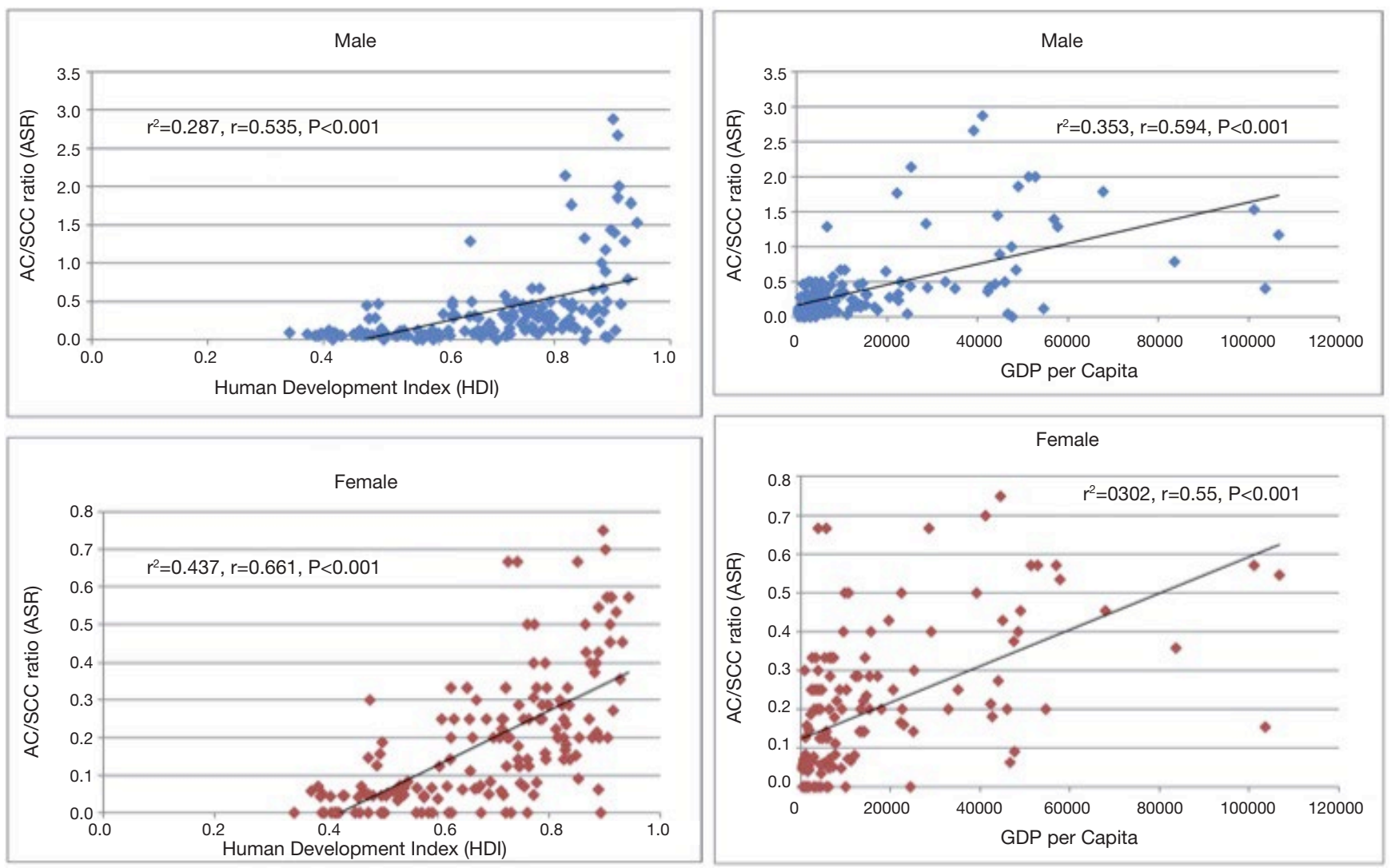

Figure 4 Relationship between the ratio of crude incidence rates of adenocarcinoma (AC): squamous cell carcinoma (SCC) and Human Development Index in male (left upper panel) and female (left lower panel). Relationship between the ratio of crude incidence rates of adenocarcinoma (AC): squamous cell carcinoma (SCC) and Gross Domestic Product per capita in male (right upper panel) and female (right lower panel). HDI is defined by life expectancy, education, and per capita income. The ratio of AC to SCC increases as an individual's HDI and GDP per capita increases.

development warrants further investigation.

\section{Helicobacter pylori}

Helicobacter pylori is a gram-negative bacteria infecting the stomach of half of the population and causing a great deal of gastrointestinal morbidity. The role of $H$. pylori in gastritis, ulceration and gastric adenocarcinoma is well established $(48,49)$, however, the role of H. Pylori in esophageal AC is controversial. There is some evidence that $H$. Pylori plays a role in each of the steps from GERD to Barrett's esophagus to dysplasia to esophageal AC (50). Eradication of $H$. Pylori can also reduce GERD symptoms and esophagitis in certain populations (51), thereby decreasing the likelihood of esophageal AC. Other meta analysis show an inverse relationship between $H$. Pylori infection and esophageal $\mathrm{AC}$ and suggest that $H$. Pylori has a protective effect against esophageal AC (52). In general, it appears that data on $H$. Pylori and esophageal AC is inconclusive and further studies are needed to properly establish the relationship between $H$. Pylori and esophageal AC whether it is protective, causal or unrelated.

\section{Adenocarcinoma in the Asian esophageal belt}

Although we see the greatest increased incidence of 
adenocarcinoma of the esophagus in the Western countries and North America, China still contributed about 18\% of all global cases in 2012, with the "Asian belt" accounting for more than $30 \%$ of all cases (Figure 1) (33). There has been a correlation between incidence and mortality of esophageal cancer versus HDI (human development index) and GDP per capita. The higher incidence, which is SCC, is seen in lower HDI and GDP countries and the incidence of adenocarcinoma is increasing in "Western" countries, which tend to have a higher GDP and HDI (53). This correlation with HDI and GDP shows that there are socioeconomic factors related to the incidence of esophageal cancer and the areas of the China that have increased incidence of AC tend to be more developed with a higher socioeconomic status (Figure 4).

\section{Prevention}

As the incidence of $\mathrm{AC}$ of the esophagus continues to rise, a focus on prevention and screening in high-risk populations is a major global health topic. The high-risk populations should include those with chronic gastroesophageal reflux disease, older age, male sex, obesity and family history. There is a definite recognition of the importance to eliminate global obesity with the creation of prevention programs, exercise campaigns, and nutrition projects. In terms of esophageal cancer as a whole, there are some policies that have been implemented regarding smoking in Western countries; however, smoking rates are not being addressed worldwide. With approximately half of all new esophageal cancer cases occurring in China, a prospective cohort protocol, National Cohort of Esophageal CancerProspective Cohort Study of Esophageal Cancer and Precancerous Lesions based on High-Risk Population (NCEC-HRP), has been developed in China focusing on its high-risk rural populations-rural areas with the highest incidence of esophageal SCC. The goal of this study is to develop a set of guidelines for esophageal cancers screening for early diagnosis, as well as identify risk factors and develop a proper database (54). Liu et al., performed a community-based study that proved the effectiveness of endoscopic upper GI screening in highrisk populations in China. Their analysis proved that after a 9 -year follow up, incidence and mortality were lowered by $43 \%$ (standardized incidence ratio $=0.57,95 \%$ CI: 0.38 0.86 ) and $53 \%$ (standardized mortality ratio $=0.47,95 \%$ CI: $0.25-0.88)$ respectively (55). The implementation of secondary prevention programs is important, as cure rates for esophageal cancer are low with five-year survival rates between $10-15 \%$ (56). This will allow for identification of early disease as currently most cases are being diagnosed in late stages.

\section{Conclusion}

Esophageal cancer is frequently a lethal disease that is often diagnosed in the late stages with a high mortality rate. As we continue to see a rise in adenocarcinoma of the esophagus, it is essential to implement prevention and screening policies for early diagnosis, which will allow for better chance of survival. The pattern of presentation of esophageal AC is different from that of SCC and is most likely due to different lifestyles and genetic backgrounds. As we note a correlation between the rise in adenocarcinoma and obesity, we can utilize this information to implement primary and secondary prevention policies in high riskpopulations. With implementation of these screening policies, such as screening endoscopy and lifestyle modification actions, further studies need to be done to determine if this will have a substantial effect on the rates of esophageal adenocarcinoma.

\section{Acknowledgments}

Funding: None.

\section{Footnote}

Provenance and Peer Review: This article was commissioned by the editorial office, Fournal of Gastrointestinal Oncology for the series "Global GI Malignancies". The article has undergone external peer review.

Conflicts of Interest: All authors have completed the ICMJE uniform disclosure form (available at http://dx.doi. org/10.21037/jgo-2019-gi-08). The series "Global GI Malignancies" was commissioned by the editorial office without any funding or sponsorship. John F. Gibbs served as the unpaid Guest Editor of the series and serves as an unpaid editorial board member of Fournal of Gastrointestinal Oncology from Jan 2019 to Dec 2020. The authors have no other conflicts of interest to declare.

Ethical Statement: The authors are accountable for all aspects of the work in ensuring that questions related to the accuracy or integrity of any part of the work are 
appropriately investigated and resolved.

Open Access Statement: This is an Open Access article distributed in accordance with the Creative Commons Attribution-NonCommercial-NoDerivs 4.0 International License (CC BY-NC-ND 4.0), which permits the noncommercial replication and distribution of the article with the strict proviso that no changes or edits are made and the original work is properly cited (including links to both the formal publication through the relevant DOI and the license). See: https://creativecommons.org/licenses/by-nc-nd/4.0/.

\section{References}

1. Thrift AP. Thrift. The epidemic of oesophageal carcinoma: Where are we now? Cancer Epidemiol 2016;41:88-95.

2. Patel N, Benipal B. Incidence of Esophageal Cancer in the United States from 2001-2015: A United States Cancer Statistics Analysis of 50 States. Cureus 2018;10:e3709.

3. Eslick GD. Epidemiology of esophageal cancer. Gastroenterol Clin North Am 2009;38:17-25, vii.

4. Keeney S, Bauer TL. Epidemiology of adenocarcinoma of the esophagogastric junction. Surg Oncol Clin N Am 2006;15:687-96.

5. Cook MB, Chow WH, Devesa SS. Oesophageal cancer incidence in the United States by race, sex, and histologic type, 1977-2005. Br J Cancer 2009;101:855-9.

6. Arnold M, Laversanne M, Morris Brown L, et al. Predicting the future burden of esophageal cancer by histological subtype: International trends in incidence up to 2030. Am J Gastroenterol 2017;112:1247-55.

7. Freedman ND, Abnet CC, Leitzmann MF, et al. A prospective study of tobacco, alcohol, and the risk of esophageal and gastric cancer subtypes. Am J Epidemiol 2007;165:1424-33.

8. McLaughlin JK, Hrubec Z, Blot WJ, et al. Smoking and cancer mortality among U.S. veterans: a 26-year followup. Int J Cancer 1995;60:190-3.

9. Carstensen JM, Pershagen G, Eklund G. Mortality in relation to cigarette and pipe smoking: 16 years' observation of 25,000 Swedish men. J Epidemiol Community Health 1987;41:166-72.

10. Iribarren C, Tekawa IS, Sidney S, Friedman GD. Effect of cigar smoking on the risk of cardiovascular disease, chronic obstructive pulmonary disease, and cancer in men. $\mathrm{N}$ Engl J Med 1999;340:1773.

11. Randi G, Scotti L, Bosetti C, et al. Pipe smoking and cancers of the upper digestive tract. Int J Cancer
2007;121:2049.

12. Wang QL, Xie SH, Li WT, et al. Smoking Cessation and Risk of Esophageal Cancer by Histological Type: Systematic Review and Meta-analysis. J Natl Cancer Inst 2017;109. doi: 10.1093/jnci/djx115.

13. Thun MJ, Peto R, Lopez AD, et al. Alcohol consumption and mortality among middle-aged and elderly U.S. adults. N Engl J Med 1997;337:1705.

14. Pandeya N, Williams G, Green AC, et al. Alcohol consumption and the risks of adenocarcinoma and squamous cell carcinoma of the esophagus. Gastroenterology 2009;136:1215-24, e1-2.

15. Prabhu A, Obi KO, Rubenstein JH. The synergistic effects of alcohol and tobacco consumption on the risk of esophageal squamous cell carcinoma: a meta-analysis. Am J Gastroenterol 2014;109:822.

16. Islami F, Ren JS, Taylor PR, et al. Pickled vegetables and the risk of oesophageal cancer: a meta-analysis. $\mathrm{Br} \mathrm{J}$ Cancer 2009;101:1641.

17. Choi YJ, Lee DH, Han KD, et al. The relationship between drinking alcohol and esophageal, gastric or colorectal cancer: A nationwide population-based cohort study of South Korea. PLoS One 2017;12:e0185778.

18. Pottern LM, Morris LE, Blot WJ, et al. Esophageal cancer among black men in Washington, D.C. I. Alcohol, tobacco, and other risk factors. J Natl Cancer Inst 1981;67:777.

19. Brown LM, Hoover R, Silverman D, et al. Excess incidence of squamous cell esophageal cancer among US Black men: role of social class and other risk factors. Am J Epidemiol 2001;153:114-22.

20. Rafiq R, Shah IA, Bhat GA, et al. Secondhand Smoking and the Risk of Esophageal Squamous Cell Carcinoma in a High Incidence Region, Kashmir, India: A Case-controlobservational Study. Medicine (Baltimore) 2016;95:e2340.

21. Lu SH, Montesano R, Zhang MS, et al. Relevance of $\mathrm{N}$-nitrosamines to esophageal cancer in China. J Cell Physiol Suppl 1986;4:51.

22. Yang CS. Research on esophageal cancer in China: a review. Cancer Res 1980;40:2633-44.

23. Islami F, Poustchi H, Pourshams A, et al. A prospective study of tea drinking temperature and risk of esophageal squamous cell carcinoma. Int J Cancer 2020;146:18-25.

24. Liu J, Wang J, Leng Y, et al. Intake of fruit and vegetables and risk of esophageal squamous cell carcinoma: a meta-analysis of observational studies. Int J Cancer 2013;133:473.

25. Yang CS, Sun Y, Yang QU, et al. Vitamin A and other deficiencies in Linxian, a high esophageal cancer 
incidence area in northern China. J Natl Cancer Inst 1984;73:1449-53.

26. Abnet CC, Lai B, Qiao YL, et al. Zinc concentration in esophageal biopsy specimens measured by $\mathrm{x}$-ray fluorescence and esophageal cancer risk. J Natl Cancer Inst 2005;97:301-6.

27. Akhtar S. Areca nut chewing and esophageal squamouscell carcinoma risk in Asians: A meta-analysis of casecontrol studies. Cancer Causes Control 2013;24:257-65.

28. Muñoz N, Bosch FX, de Sanjosé S, et al. Epidemiologic classification of human papillomavirus types associated with cervical cancer. International Agency for Research on Cancer Multicenter Cervical Cancer Study Group. N Engl J Med 2003;348:518-27.

29. Zhang SK, Guo LW, Chen Q, et al. Prevalence of human papillomavirus 16 in esophageal cancer among the Chinese population: a systematic review and meta- analysis. Asian Pac J Cancer Prev 2014;15:10143-9.

30. Cancer Genome Atlas Research Network; Analysis Working Group: Asan University, et al. Integrated genomic characterization of oesophageal carcinoma. Nature 2017;541:169-75.

31. Guo L, Liu S, Zhang S, et al. Human papillomavirusrelated esophageal cancer survival: A systematic review and meta-analysis. Medicine (Baltimore) 2016;95:e5318.

32. Liyanage SS, Rahman B, Ridda I, et al. The aetiological role of human papillomavirus in oesophageal squamous cell carcinoma: a meta-analysis. PLoS One 2013;8:e69238.

33. Arnold M, Soerjomataram I, Ferlay J, et al. Global incidence of oesophageal cancer by histological subtype in 2012. Gut 2015;64:381-7.

34. Zeng H, Zheng R, Zhang S, et al. Esophageal cancer statistics in China, 2011: Estimates based on 177 cancer registries. Thorac Cancer 2016;7:232-7.

35. Buas MF, Vaughan TL. Epidemiology and risk factors for gastroesophageal junction tumors: understanding the rising incidence of this disease. Semin Radiat Oncol 2013;23:3-9.

36. Nelson RA, Smith DD, Schwarz RE. Nelson R.A., et al. Epidemiology and Staging of Upper Gastrointestinal Cancer. In: Morita SY, Balch CM, Klimberg V, et al. Eds. Shane Y. Morita, et al.eds. Textbook of Complex General Surgical Oncology New York, NY: McGraw-Hill; Available online: http://accesssurgery.mhmedical.com/ content.aspx? bookid $=2209$ \&sectionid $=168942517$.

37. "Obesity and Overweight." World Health Organization, World Health Organization. Available online: www.who. int/news-room/fact-sheets/detail/obesity-and-overweight.
38. Cameron AJ, Lomboy CT, Pera M, et al. Adenocarcinoma of the esophagogastric junction and Barrett's esophagus. Gastroenterology 1995;109:1541-6.

39. Hvid-Jensen F, Pedersen L, Drewes AM, et al. Incidence of adenocarcinoma among patients with barrett's esophagus. N Engl J Med 2011;365:1375.

40. Grover K, Gregory S, Gibbs JF, Emenaker NJ. A discussion of the gut microbiome's development, determinants, and dysbiosis in cancers of the esophagus and stomach. J Gastrointest Oncol 2020. doi: 10.21037/ jgo-2019-gi-07.

41. Eusebi LH, Ratnakumaran R, Yuan Y, et al. Global prevalence of, and risk factors for, gastro-oesophageal reflux symptoms: a meta-analysis. Gut 2018;67:430-40.

42. Savarino E, de Bortoli N, De Cassan C, et al. The natural history of gastro-esophageal reflux disease: a comprehensive review. Dis Esophagus 2017;30:1-9.

43. Schneider JL, Corley DA. The Troublesome Epidemiology of Barrett's Esophagus and Esophageal Adenocarcinoma. Gastrointest Endosc Clin N Am 2017;27:353-64.

44. Gammon MD, Schoenberg JB, Ahsan H, et al. Tobacco, alcohol and socioeconomic status and adenocarcinomas of the esophagus and gastric cardi. J Natl Cancer Inst 1997;89:1277-84.

45. Han SH, Hong SJ. Transient lower esophageal sphincter relaxation and the related esophageal motor activities. Korean J Gastroenterol 2012;59:205-10.

46. Lagergren J, Bergstrom R, Adami HO, et al. Association between medications that relax the LES and risk for esophageal adenocarcinoma. Ann Intern Med 2000;133:165-75.

47. Alexandre L, Broughton T, Loke Y, et al. Meta-analysis: risk of esophageal adenocarcinoma with medications which relax the lower esophageal sphincter. Dis Esophagus 2012;25:535-44.

48. Blaser MJ, Perez-Perez GI, Kleanthous H, et al. Infection with Helicobacter pylori strains possessing cagA is associated with an increased risk of developing adenocarcinoma of the stomach. Cancer Res 1995;55:2111-5.

49. Lanas A, Chan FKL. Peptic ulcer disease. Lancet 2017;390:613-24.

50. Kountouras J, Chatzopoulos D, Zavos C, et al. Helicobacter pylori infection might contribute to esophageal adenocarcinoma progress in subpopulations with gastroesophageal reflux disease and Barrett's esophagus. Helicobacter 2012;17:402-3.

51. Kountouras J, Zavos C, Chatzopoulos D, et al. 
Helicobacter pylori and gastro-oesophageal reflux disease. Lancet 2006;368:986.

52. Polyzos SA, Zeglinas C, Artemaki F, et al. Helicobacter pylori infection and esophageal adenocarcinoma: a review and a personal view. Ann Gastroenterol 2018;31:8-13.

53. Wong MCS, Hamilton W, Whiteman DC, et al. Global Incidence and mortality of oesophageal cancer and their correlation with socioeconomic indicators temporal patterns and trends in 41 countries. Sci Rep 2018;8:4522.

54. Chen R, Ma S, Guan C, et al. The National Cohort of Esophageal Cancer-Prospective Cohort Study of

Cite this article as: Grille VJ, Campbell S, Gibbs JF, Bauer TL. Esophageal cancer: the rise of adenocarcinoma over squamous cell carcinoma in the Asian belt. J Gastrointest Oncol 2021;12(Suppl 2):S339-S349. doi: 10.21037/jgo-2019-gi-08
Esophageal Cancer and Precancerous Lesions based on High-Risk Population in China (NCEC-HRP): study protocol. BMJ Open 2019;9:e027360.

55. Liu M, He Z, Guo C, et al. Effectiveness of Intensive Endoscopic Screening for Esophageal Cancer in China: A Community-Based Study. Am J Epidemiol 2019;188:776-84.

56. Gibbs JF, Rajput A, Chadha KS, et al. The changing profile of esophageal cancer presentation and its implication for diagnosis. J Natl Med Assoc 2007;99:620 6. 